\title{
LA PUESTA EN RELACIÓN
}

\author{
POR \\ PATRick Chamoiseau
}

En su libro El espíritu de las leyes, Montesquieu dice que recibimos tres tipos de educación diferentes o contrarios: la educación de nuestros padres, la educación de nuestros maestros y, finalmente, la educación del mundo. Concluye afirmando que la educación que recibimos del mundo trastorna todas las ideas que se podrían obtener de las dos primeras.

Por supuesto, al referirse a la educación del mundo, Montesquieu hablaba de la sociedad civil de su tiempo. Pero si aplicamos esta reflexión a nuestra situación actual, vemos que podría funcionar igual de bien, ya que todos nosotros recibimos una educación que invalida todo lo que habíamos cosechado antes. Esta terrible educación no solo proviene de la sociedad civil, sino también, y sobre todo, de la totalidad del mundo. Independientemente de dónde estemos, nos enfrentamos ahora al resto del mundo. Nuestro horizonte no es solo nuestro campanario o los límites de nuestro territorio, en la actualidad, constituido por la conciencia más o menos clara de que somos los habitantes de un mismo y único planeta. Ahora las naciones, las culturas y los pueblos se encuentran en la fatalidad de un destino común.

Mucho se ha discutido sobre la cuestión de la globalización y sus consecuencias, y mi intención no es volver sobre ese tema. Pero me parece que para cuestionar las nociones mismas de centro y periferia, tenemos que examinar el proceso de globalización. ¿Por qué? La razón es que con este proceso se invalida de manera fundamental toda la constitución de los principios habituales de nuestra existencia en el mundo y las relaciones que las personas pueden tejer actualmente entre sí.

Se podría decir que desde el momento en que Cristóbal Colón pisó la playa de una isla en el continente americano, el mundo comenzó a ser mundo. Es decir, se desdibujaron los límites de determinadas culturas y territorios para entrar en un proceso de unificación o globalización que nunca iba a cesar, y que, a partir de los años ochenta del siglo XX, experimentaría un ritmo sin precedentes. Esta unificación acelerada del mundo tiene un origen que todos conocemos. Es, por supuesto, el increíble desarrollo 
de las nuevas tecnologías de la información y la comunicación. También proviene de la expansión de la ideología global del indiscutible dogma neoliberal capitalista que transforma la tierra en un mercado unificado. Una ideología que exige que todas las personas del mundo se conviertan en consumidores y se sometan a una misma lógica mercantil. Volveremos sobre este aspecto que será el centro de mi intervención, pero veamos primero esta idea de globalización.

El mundo se ha convertido en el mundo por medio de sus aspectos comerciales, financieros y mercantiles. Los consorcios capitalistas se encuentran ahora en todas partes. Su poder (sin patria, sin fronteras y a menudo sin rostro) es generalmente mucho mayor que el de la mayoría de los Estados. Esto provoca una estandarización global de los gustos y costumbres. Nos anima a comportamientos que contradicen las normas y ponen en peligro la belleza y la riqueza de nuestra humanidad, es decir, la infinita diversidad de pueblos, culturas y visiones de mundo. Esta globalización capitalista es, por supuesto, negativa. Y para comprender sus fundamentos y sus orígenes tenemos que volver a un concepto clave, el de Territorio.

Una cultura tradicional se desarrolla, por lo general, en términos bastante específicos. Una comunidad de hombres se establece en una porción de tierra, o se instala de manera fija o móvil, y, para legitimar el dominio de la tierra, se crea una explicación de la creación del universo: una génesis. Y, de esta génesis, la comunidad extrae una narración, un relato que se constituirá como mito fundacional. Este mito fundacional se va a articular eventualmente con otra narración, más desarrollada, más directa, y que será la Historia de este pueblo. Este hilo, que desciende directamente desde esa génesis y que se extiende en el relato de la comunidad, fomenta la legalización de la posesión de tierras por parte de la comunidad misma. Por lo tanto, todas las culturas tradicionales tienen una fuerte conciencia de la legitimidad casi divina de su existencia en la tierra. Todos se definen con mayor frecuencia como "hombres" o "seres humanos", considerando al resto de la humanidad como bárbaro o extraño, no solo a su tierra, sino también al orden mismo de su universo: todo lo que no es de ellos es distorsión o error. Esta fuerte legitimación creará los Territorios.

El Territorio es una empresa en un lugar, de donde se tratará de excluir a las otras existencias. Esta empresa legitimará las narrativas, tanto reales, como ficcionales y simbólicas, que serán las culturas. Estas culturas se diferenciarán de otras, generando así la noción de identidad. Esto ocurre cuando el Otro aparece en el horizonte, amenazando mi posesión de tierra, yo tomo en cuenta lo que me pertenece, lo que no es él, o de él, y lo que lo excluye. La identidad es esta narración de mí mismo (al igual que la narrativa concreta, ficticia y simbólica de la cultura de la que procede) que sirve para proteger mi vida. Se utiliza para confirmar la idea de que mi ser es el centro de la creación, el centro del mundo, y por lo tanto, debe oponerse a la otra. El Territorio estará marcado con banderas, himnos marciales, fronteras, marcas diversas más o menos inspiradas

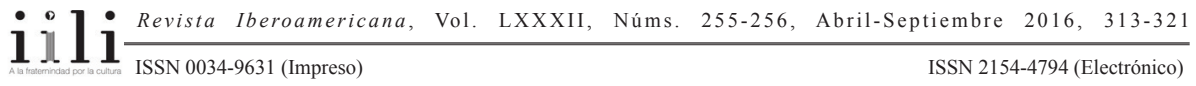


en las fieras que delimitan su área vital. Pocas culturas escapan de este mecanismo de exclusión del Otro, pero en Occidente, este síndrome se arraiga debido al surgimiento de los Estados-nación, un giro fatal para el mundo entero.

Es a través de las certezas inscritas en sus territorios que los países occidentales justifican su expansión hegemónica: el colonialismo, el imperialismo y la dominación actual. El occidental está convencido de su legitimidad sobre su Territorio, convencido de estar en el centro y en la culminación de todos los asuntos humanos. Piensa que atiende un llamado a extenderse sin control para ir a dictar orden sobre la vida. La famosa carga del hombre blanco asociada con el concepto de universalidad. Él se lanzará sobre el mundo conocido, desembarcará en Asia, África, América, con entusiasmo y gestos casi idénticos. No importa si esto se hace en inglés, francés, español o portugués, cuando entierre su bandera o haga algún tipo de marca, él dirá: “¡Esta tierra es mía!”. Estará cada vez más convencido de haber descubierto un lugar que se encuentra fuera de la historia, fuera de la conciencia; su labor será la de cristianizar y civilizar a los que pueda imponer sus concepciones y orden de las cosas. Los occidentales comenzaron a explotar el mundo, dando la ilusión de llevar a los bárbaros la belleza, la verdad, lo justo. Sus Territorios originales se extendian hasta el infinito, uno frente al otro para potenciar al máximo su propia... Esta es la lógica del territorio que instaura el mundo de los centros y las periferias en una escala nunca antes conocida. Esta es la lógica del territorio que hace de Occidente el centro dominador del mundo y el motor de su unificación.

En el mundo antiguo siempre habían existido centros de conexiones urbanas donde se podían encontrar los comerciantes provenientes de los cuatro puntos cardinales. Los centros que conoceríamos en el mundo moderno, y que irradiarían todo el planeta, provenían de territorios que se extendían por el mundo entero a merced de su voluntad y que sometían la realidad y la diversidad de los seres vivos a la lógica de sus ganancias e intereses.

La globalización actual ha reunido a los antiguos centros coloniales e imperialistas en un centro prácticamente subliminal, que incluye, por supuesto, los espacios de la vieja Europa conquistadora y los actuales Estados Unidos. Pero ahora, las fuerzas capitalistas que emergen tienden a despojarse de toda participación geográfica, nacional o patriótica, para convertirse en inmateriales. En la globalización de los mercados, que se constituye como último centro del mundo y que gobierna el resto del planeta, los poderes financieros más importantes, las grandes empresas trans- y multinacionales, enmarcadas por una ideología difusa capitalista, extienden sus valores y conformaciones, transforman toda la Tierra en una vasta periferia de dos entidades poderosas, que en la actualidad están constituidas por Europa y Estados Unidos.

Esta es la extensión de los territorios que dará origen a las nociones de centro y periferia. Por lo tanto, cualquier periferia estará, por definición, al servicio del centro y de la lógica de sus intereses. Cualquier centro establecido se establece dentro de la

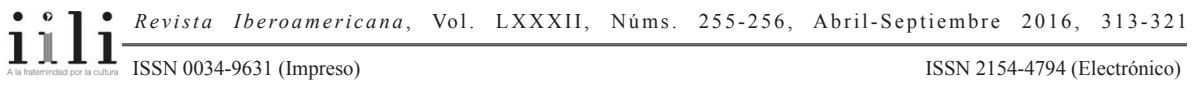


dialéctica de su propio desarrollo como un diseño monolítico que contradice y anula la diversidad de posibilidades. Cualquier centro crea, incluso si somos cuidadosos, los silencios y los resentimientos, las estandarizaciones y el agotamiento. Un desgaste irremediable que se vuelve hacia él, en un solo sentido de enriquecimiento verdadero de todos los procesos de desarrollo. Los imperios de todos los tiempos (del Imperio romano a las empresas colonialistas) también se han derrumbado por esta razón.

Es cierto que hoy Europa habla de periferia y de ultraperiferia, no con una intención dominante, pero con el fin de identificar las áreas de sí misma que no gozan de los beneficios de la parte central más rica, las zonas remotas cuyos equipos tecnológicos no tienen el mismo nivel y deben estar acompañadas en su desarrollo. Pero establecer esta intención tan loable bajo las nociones de centro y periferia es sacrificarse a una lógica insidiosa, que tiene como objetivo centrar el modelo de organización al que tiende y del cual parte la periferia. Se trata de una fatalidad insidiosa que hace que las ayudas, los apoyos, los acompañamientos de cualquier tipo, se encuentren en una dialéctica de integración al centro. En la integración, hay primero desintegración y luego recomposición de acuerdo con un paradigma que proviene del centro referencial.

También puedo decir que las palabras no son inocentes. Cada vez que surgen estos vocablos de centro y periferia, estamos lejos de ofrecer la mínima oportunidad para exaltar la necesidad de la diversidad. Cerramos la puerta de nuestro espíritu a la oportunidad de lo posible, y contradecimos aquello que hace de lo viviente su virtud, es decir, el laberinto inmenso de opciones y estrategias. Entre centro y periferia no pueden prosperar valores humanos reales. Aunque el centro se desarrolle, se modernice, aunque el centro amplíe las capacidades de consumo y aumente los niveles de vida, el centro tiende a crear, a mediano o largo plazo, lo mismo y la unicidad. Por eso, me parece que entre el centro y la periferia no puede existir más que una puesta bajo relación y nunca una puesta en relación. Y, si me permiten, me centraré en estos dos términos.

En la globalización del mercado todos los pueblos están unidos entre sí, pero en esta configuración, no hay nada más que una puesta bajo relación. Este tipo de relación crea modelos, estándares, uniformidades. En la globalización capitalista que se extiende ante nosotros, se propone eliminar la diversidad, los imaginarios de la personas, se reduce su genio a una sola norma. No se les permite sino entrar a un proceso insidioso al que se deben ajustar. En la puesta bajo relación hay más transmisiones que comunicaciones reales. Más sujeción que asociación. Más propagación que intercambio. Más monólogo organizador que diálogo o voz humana. Se encuentran circuitos de comunicación en un solo sentido, pero no es un valor relacional único -como no encontramos ningún valor relacional en ese baile al que invitamos a la gente de Martinica alrededor de un crucero de turistas-.

En la puesta bajo relación hay un tráfico de influencias que nos afectan a nosotros o que nos vienen impuestas y sufrimos de una manera más o menos perceptible. Ello

$111 \frac{\text { Revista Iberoamericana, Vol. LXXXII, Núms. 255-256, Abril-Septiembre 2016, } 313-321}{\text { ISSN 2154-4794 (Electrónico) }}$ 
nos transforma, nos modela y elimina nuestras particularidades, nuestras diferencias. Estamos en condiciones de recibir todo, sin poder dar una retroalimentación que sea determinante o fundamental. La puesta bajo relación es vertical, al igual que los árboles de higo malditos, cuya sombra no permite que algo germine. Pero sabemos cómo, en los ecosistemas, la vida crece y se nutre de la diversidad. Sabemos que cada vez que aparece una hegemonía, una sola voz, una expansión que inclina bajo su mando todas las otras presencias, hay primero grandes silencios, y luego se rompe una cadena, después, un colapso general que socava el principio mismo de la vida. La vida no sabe de centros y periferias. La vida no conoce la puesta bajo relación. El colonialismo, el imperialismo, la dominación tecnológica y todos los evangelios del "desarrollo" son la puesta bajo relación.

En la globalización de los mercados, la mayoría de las personas están puestas bajo relación y, por lo tanto, están sometidas a la influencia de un camino que conduce a la uniformidad y a un consumo normalizado. Sin embargo, a pesar de esta clasificación, la riqueza producida, el progreso técnico, como también los descubrimientos médicos, no benefician a todos. Millones de personas están muriendo de SIDA en África; viejas enfermedades medievales aparecen en todo el mundo, en estos grandes manglares urbanos que están sedimentados alrededor de las ciudades. Y estos países, aún bajo la influencia de un centro, no se benefician de los avances médicos que están al otro extremo de la relación. El mundo está conectado, sin embargo sus vertientes no son irrigadas de la misma manera, como si la globalización mercantil consistiera en una red de pequeñas aspiradoras que tienden a vaciar y suprimir todos los demás espacios. Pero hay algo más sorprendente.

Cuando la puesta bajo relación permite una relativa adhesión a los programas de desarrollo, las subvenciones, que hacen posible evitar las muertes por hambre, la submedicalización y otras catástrofes que prevalecen en el mundo, crea, en todas las poblaciones, fenómenos anestésicos de pasividad, falta de imaginación y falta de proyección. Un síndrome de irresponsabilidad, dependencia y asistencialismo. En todas las periferias declaradas, hay personas que se sienten incapaces de existir en el mundo en términos de soberanía. Pueblos que se deleitan diluyéndose en el centro dominante o asimilándose a él. Y, paradójicamente, es el centro el que se esfuerza por superar esta pasividad. Es el centro el que se desespera, el que fomenta la imaginación, la creación de proyectos, el surgimiento de las ideas, y el que se enfrenta día a día al peso de la pasividad. Recuerden que son los comisionados europeos los que se encuentran desesperados por todos esos recursos que están disponibles para nosotros, y que en gran medida siguen estando sin utilizar o subutilizados. Recuerden cómo se vuelve necesario inventar trucos, hacer amenazas y gastar energía, para que las ayudas que están a nuestra disposición se movilicen en un tiempo razonable. El destino de cada centro está en la desesperación a causa de sus periferias, puesto que en la noosfera de los centros y las periferias, no hay lugar para otra cosa que no sea un desgaste mortal.

$111 \frac{\text { Revista Iberoamericana, Vol. LXXXII, Núms. 255-256, Abril-Septiembre 2016, } 313-321}{\text { ISSN 0034-9631 (Impreso) }}$ 
Y finalmente, hay que decir que la puesta bajo relación está aislada del resto del mundo. El Caribe es difícil de constituir, porque todos sus Estados están puestos bajo relación. Las relaciones con nuestro entorno inmediato son insuficientes o inexistentes, debido a que la puesta bajo relación no crea el tráfico y el horizonte deseable hacia el centro organizador. Así, cuando el mundo se abre, se une y se conecta, pueblos enteros viven y planifican en las periferias de una transmisión cercana a sí misma. Mientras el mundo se une y se conecta, los pueblos periféricos no tienen horizonte que los cubra, de manera más o menos benevolente, de sus respectivos centros.

Pero donde el peligro crece, crece también lo que se salva. $\mathrm{Y}$ es por eso que incluso en esta globalización se producen algunos fenómenos positivos. Allí, en el mercado de la globalización, aparece una dinámica inesperada que debe destacarse y que Glissant denomina mundialidad. La mundialidad quiere decir que el mundo es ahora consciente de su unidad. Esto significa que en cualquier parte del mundo en la que nos encontremos, sea cual sea nuestra cultura, nuestra lengua, nuestra identidad, el mundo nos atraviesa, nos habita y nos condiciona. Nunca la diversidad del mundo se había visto tan amenazada, nunca había sido tan consciente de sí misma y había influido tanto en nuestras concepciones e imaginarios. Los pueblos como los nuestros (que son pueblos creole, pueblos mosaico) no tienen génesis ni mito fundador. Nuestros pueblos aparecen en el remolino de la diversidad, y no pueden ser considerados fuera de un mosaico abierto sobre la diversidad del mundo.

El mundo de hoy está conectado en sus partes más ínfimas, y por lo tanto se vuelve impredecible e incontrolable. Ahora es un caos-mundo, como lo diría Glissant. O aun a la manera de los alquimistas: un mundo-piedra. Esta nueva complejidad hace que cualquier mínimo evento ocurrido en cualquier rincón de la Tierra pueda alterar todo el planeta. Nada puede ser ahora manejado en la escala de una nación o un Estado. La lucha contra las grandes plagas debe ser considerada mediante la participación de todos y en presencia de todos. Los centros dominantes habían creído ir a las bienaventuranzas de un progreso permanente, hacia el final de la historia, hacia el dominio total de la naturaleza, hacia una verdad última que nos sería dada por la ciencia todopoderosa. Y han descubierto, a medida que el mundo se conecta, el desencadenamiento de las historias, la irrupción del desorden, las lógicas caóticas o fractales, las alteraciones proteicas del fanatismo y el terrorismo. Esta nueva complejidad del mundo contradice activamente la noción de territorio, como también las de centro y periferia. Las fronteras ya no sirven mucho, las periferias se enfrentan cada vez más a la presencia de su entorno inmediato, y los centros están cada vez más confundidos en sus programas debido a los trastornos de lo imprevisible, la alta frecuencia de lo incierto y lo inesperado.

En un mundo que se ha vuelto impredecible e imprevisible, en esta nueva complejidad, el todo está en cada parte y cada parte condiciona el todo de manera inmediata y sobredimensionada. Y si la estandarización, la uniformidad, la dominación insidiosa se 
propagan y se amplían, también se amplían el deseo o el impulso de la diversidad, las reivindicaciones particulares, las necesidades de todas las presencias del mundo que se adaptan muy rápidamente a los cambios, a los vaivenes e incertidumbres de su entorno. Una tormenta general que ninguna planta de energía puede detener o gestionar a distancia.

Las identidades cerradas, el fundamentalismo bárbaro, los fanatismos religiosos, la pureza étnica son ahora los principales conflictos del mundo. Estos son los elementos que se resisten a la diversidad de una puesta bajo relación, que contradicen las dinámicas esenciales de la mundialidad. Por desgracia, estas resistencias se conciben de manera obsoleta, muestran su antiguo absolutismo y las viejas identidades. Contra la lengua dominante, muestro mi lengua. Contra tu bandera, yo levanto mi bandera. Contra tu absolutismo, yo erijo mi absolutismo. Un antiguo imaginario se levanta y lucha inadecuadamente contra la globalización capitalista que está en marcha. Y esta resistencia inadecuada hace pasar la libertad y la justicia al otro lado de la línea. Para encontrar los acentos de una resistencia que sea justa y eficiente, ahora debemos promover un imaginario que no esté en la lógica del Territorio, ni en las nociones de centro y periferia, ni en una puesta bajo relación. Y es aquí donde aparece la noción que se opone directamente a la de puesta bajo relación, y es la de puesta en relación.

Cristóbal Colón inauguró la puesta bajo relación. Nuestra tarea hoy en día, sin importar el área en la que nos ocupemos, es promover un nuevo imaginario contra la dominación, la conquista, la estandarización y la uniformidad, a favor de una auténtica participación; el intercambio nos transforma, sin hacernos perder o desnaturalizarnos, tal como lo propone Glissant.

Debemos promover la puesta en relación. La puesta en relación no es vertical. Es horizontal. Está presente en la interacción positiva de la conciencia de cada uno acerca de las diversidades del mundo conectado. En la puesta en relación se respetan las diversas culturas y pueblos, y de hecho toda su riqueza. Este es el gran movimiento del dar y recibir, y la refrescante dinámica de dar-con. Este es un concierto de diversidades conservadas que rompe el campo cerrado de los territorios, las lenguas y las identidades de los depredadores agresivos del Otro. La puesta en relación invalida las nociones de centro y periferia para permitir la aventura de las verdaderas redes de solidaridad, la comunicación verdadera, las complejidades multipolares, las afiliaciones múltiples y las alianzas fructíferas. No se aísla, se une y se conecta. No se integra, acepta al Otro en su opacidad y lo invita a compartir y a aliarse. No tiene ningún centro o periferia, porque se extiende como un rizoma, una multiplicación de los nodos que se abren e irradian de manera autónoma su entorno, para suscitar otros nodos y otras radiaciones. Se trata de un nuevo imaginario que nos ayudará a romper con los viejos patrones de la singularidad y las nuevas formas insidiosas de hegemonía y dominación.

La puesta en relación abre a la Relación. Y es por esto que quiero centrarme en esta noción de Relación que constituye la columna vertebral de la obra de Édouard 
Glissant. La idea de Relación es a la vez un acta y un proyecto. En él se describe la realidad de un mundo actual con todos sus componentes conectados. Un mundo que ahora se constituye como una totalidad abierta, imprevisible, y que Glissant denomina un todo-mundo. La idea de Relación es también un proyecto en el que se pretende instalar una fantasía que yo llamaría el imaginario de la diversidad o el imaginario de la complejidad. Es a partir de la Relación que debemos tener en cuenta esta nueva situación que hace que la humanidad esté conectada entre sí en las solidaridades antagonistas y complementarias que constituyen su vitalidad irreductible. Es con la idea de la Relación que entendemos que nada absoluto es posible, y que la sombra y la luz son inseparables, como una misma cosa.

La identidad en Relación no es más exclusiva del Otro. Se convierte en relacional. Yo me defino a mí mismo, no mediante la exclusión del Otro, sino en la dinámica de mi relación con el Otro. Soy aún más yo mismo cuando estoy en contacto con la diversidad de los otros. Me afirmo más a mí mismo cuando concibo la posibilidad de cambiar en mis interacciones con el Otro, sin hacerme perder o desnaturalizarme, ya que mi yo esencial está ahora en la fluidez abierta de mi presencia en el mundo. Esta es la idea de Relación que permite la comprensión de las identidades plurales y las múltiples pertenencias. Eso es lo que nos permitirá construir alianzas diferentes a imperios, y poner en práctica organizaciones sociales que sean multi-trans-culturales y multi-trans-raciales.

Con la idea de Relación, podemos entender que Martinica es a la vez, y por mil razones fundamentales, del Caribe, de las Américas, y también de África y de Europa. $\mathrm{Y}$ es a partir de esta complejidad, que debemos considerar las modalidades de nuestra emergencia en el caos-mundo. Nos permite entender cómo sería más bello y saludable que nuestro país erigiera en sí mismo una autoridad soberana, y que esta autoridad pudiera reconstruir su verdadera relación con el Caribe, las Américas, Francia, Europa, África y todas las entidades del mundo.

Es con la idea de Relación que podemos entender que tenemos que transformar nuestros territorios en lugares. El territorio se aísla allí, en el lugar, habitado por la diversidad, tendiente a irradiar de una manera compleja, en un juego de alianzas, de solidaridades e intercambios. El mundo está constituido por una constelación infinita de lugares que podrían desarrollar una unidad sin unicidad. Una unidad que no puede ser considerada sino en la diversidad y que permite su exaltación. En resumen, una unidad abierta. Es por el imaginario de la Relación que podemos lograr nuestra verdadera unidad, nuestra más profunda unidad, que hace el firmamento de nuestras diferencias y nuestras soberanas proyecciones.

Acontinuación, estableceremos lo que nos corresponde en el concierto de la Relación.

Cerremos los ojos por un momento para imaginarnos a nosotros mismos en esta nueva educación que nos da el caos-mundo. Ahora estamos todos en el centro de nosotros mismos, juntos en torno a un valor que podemos sacralizar, y es el de la

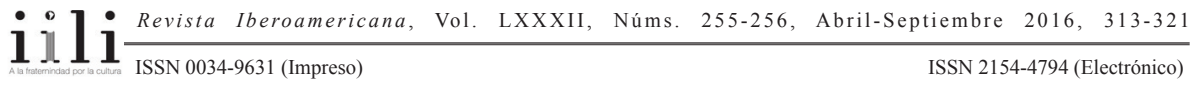


diversidad. Nos reunimos en torno al principio de la democracia, el laicismo, la igualdad entre hombres y mujeres, el re-encantamiento de la vejez, la igualdad y la libertad garantizada para todos. Convocamos a la libertad individual que fomenta la solidaridad comunitaria, y llamamos a estos vínculos comunitarios que permiten el desarrollo de nuestra individualidad. Decimos juntos que todos los pueblos tienen el derecho de controlar su destino, y es nuestro deber acompañarlos en este difícil camino. Creamos juntos, en una verdadera Razón que no se desvanezca en la racionalidad, sino que se sepa concebir en lo irracional y lo irracionalizable. Sabemos mejor juntos, respetar las diferencias, las opacidades de las culturas y personas. Estamos juntos de acuerdo, con la idea de una ciencia al servicio de la humanización del hombre, y que nos permita inscribirnos mejor, de manera modesta y durable, en las armonías y desórdenes de la naturaleza y el universo. Sabemos que el desarrollo es una orden, pero el desarrollo de cada uno es un canto de respeto e intercambio. Solo estamos esperando la gran noche, o el advenimiento de una feliz fraternidad final; tomamos un camino duro que hemos construido en su dificultad y que incluso nos mejora en su sendero... Estos son todos los valores que, en su interacción, en verdad nutren la Relación. Son lo que nos permite vivir juntos, a la altura del hombre; el poco tiempo que se nos da es para ser mejores.

Entonces oigo la respuesta habitual: “jeso es una utopía!”. Yo respondo de antemano: hay en la utopía algo de más de oxígeno y de posibilidades de transformación que en los grandes palacios desencantados del realismo y la lucidez.

Traducción de Eduardo Antonio Silva Peña

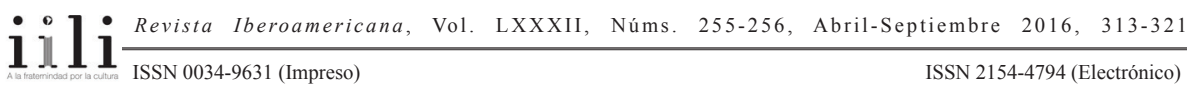


